\title{
Study on Lateral Deformation and Failure Characteristics of Coal Based on Different Confining Pressures
}

\author{
Jian-jun Ren ${ }^{(D)},{ }^{1}$ Shan-Yang Wei $\mathbb{D D}^{2},{ }^{2}$ Shi-Hai Shu, ${ }^{1}$ and Wei-Dong Luo ${ }^{3}$ \\ ${ }^{1}$ College of Physics and Engineering, Xingyi Normal University for Nationalities, Xingyi 562400, China \\ ${ }^{2}$ School of Mining, Guizhou University, Guiyang 550025, China \\ ${ }^{3}$ Guizhou Panjiang Coal Power and Electricity Group Technology Research Institute Co., Ltd., Guiyang 550081, China \\ Correspondence should be addressed to Shan-Yang Wei; sywei1@gzu.edu.cn
}

Received 31 July 2021; Accepted 18 August 2021; Published 1 September 2021

Academic Editor: Zhigang Tao

Copyright ( $\odot 2021$ Jian-jun Ren et al. This is an open access article distributed under the Creative Commons Attribution License, which permits unrestricted use, distribution, and reproduction in any medium, provided the original work is properly cited.

To study the lateral deformation characteristics of coal under different confining pressures, coal compression experiments with confining pressures of $0 \mathrm{MPa}, 3 \mathrm{MPa}, 5 \mathrm{MPa}$, and $7 \mathrm{MPa}$ were conducted under the same loading rate by using the TAW-2000 electrohydraulic servo rock mechanics experimental machine. The results of the study showed the following: at the initial stage of loading, the lateral strain of coal was about $12.22 \%-46.9 \%$ of the axial strain at the elastic deformation stage and $41.18 \%-64.96 \%$ of the axial strain at the inelastic deformation to peak stress stage. Compared with the experiment under $0 \mathrm{MPa}$ confining pressure, the growth rate of the lateral strain of the coal under $3 \mathrm{MPa}, 5 \mathrm{MPa}$, and $7 \mathrm{MPa}$ confining pressures was much smaller than that of the corresponding axial strain. When the coal was damaged under different confining pressures, the lateral strain was maintained at about $0.6 \times 10^{-2}$. Based on the field verification, we proposed that the lateral strain during the coal failure and the nonlinear region of the lateral axis ratio changing with time can be used as potential parameters for predicting the coal failure.

\section{Introduction}

Because of the impact of excavation, the coal wall of the coal roadway and the coal wall of the working face change from the initial three-way force to the one-way force so that the coal wall of the roadway and the coal near the coal wall of the working face bear the weight of rock strata above the excavation space. The weight causes an increase in the supporting pressure of the coal near the coal wall of the roadway and the working face, causing the coal near the coal wall to expand to the side of the goaf, ultimately resulting in the spalling of roadway coal wall and working face coal wall. That is, under the support pressure, the coal body on one side of the goaf of the coal wall will produce lateral expansion deformation. In practical engineering applications, it is of great significance to study the lateral deformation and lateral deformation characteristics of coal under different surrounding rock pressures to control the expansion deformation of coal rib, to guide roadway support, and to grout reinforcement of coal rib.
Scholars in China and abroad have carried out a lot of research on the lateral deformation characteristics of rocks. Based on the triaxial test results of granite under different confining pressures, Jingxiang et al. analyzed the lateral deformation characteristics of granite and proposed that the brittleness characteristics of rock samples can be comprehensively reflected from the change law and magnitude of brittleness [1]. Guojun et al. believed that, under the continuous action of cyclic loading and unloading, the failure of rock is a cumulative process. The growth trend of axial and lateral cumulative irreversible strains under cyclic loading is linear, and the increase of confining pressure can effectively limit the lateral cumulative irreversible strain of rock [2]. Based on the triaxial unloading seepage test results under different initial confining pressures and unloading rates, Rubin et al. obtained the lateral deformation characteristics. In these tests, volumetric dilatancy characteristics of sandstone changed significantly with the increase of initial confining pressure and unloading rate during unloading failure of sandstone [3]. Using an MTS815 electrohydraulic 
servo-controlled rigid testing machine, Memetyusup et al. conducted unloading/decreasing confining pressure tests with constant axial deformation. The test results indicated that, with the decrease of the confining pressure, the lateral expansion of rock samples continued, and the axial stress decreased [4]. Dong et al. proposed that the axial stress of rock can be determined by its axial strain before the peak, and it is controlled by lateral deformation after the peak, and it gradually decreases to residual strength with the increase of lateral deformation [5].

Compared with rock, coal has different characteristics in different directions. It also has low strength and undergoes a large deformation under a given loading process. Zhenqian et al. investigated the lateral deformation characteristics of coal under different loading rates by using the TAW-2000 electrohydraulic servo rock mechanics experimental system. They concluded that the lateral strain was the same when the first axial stress dropped under different loading rates, and the lateral strain was used as the control variable to predict the failure of coal [6]. Yongping carried out uniaxial and triaxial compression tests on typical soft and hard coal rock samples by MTS815 electrohydraulic servo rock mechanics testing machine. The results demonstrated that the strength, yield axial strain, and lateral deformation characteristics of soft and hard coal rock were greatly different due to the different internal structures of soft and hard coal rock and the different development degrees of pores and cracks. The internal damage evolution characteristics of coal and rock can be characterized by lateral plastic deformation damage [7]. Mingqing observed that there was a typical step-like drop after the peak stress of hard coal with impact tendency, and the significant increase of lateral axis ratio was mainly after the peak stress [8]. Tarasov and Potvin believed that the existence of surrounding rock can affect the brittleness of rock [9]. Guo et al. investigated the lateral deformation of strip coal pillar in Tangkou Coal Mine with a mining depth of over $1000 \mathrm{~m}$. They concluded that, in deep mining, the accumulation and release of energy cause discontinuous damage in the heterogeneous coal mass, and the lateral deformation of coal pillar shows discontinuity and mutation characters [10-12].

In summary, the lateral deformation characteristics and laws of rock under triaxial compression [13-15] and the axial deformation characteristics of coal under different confining pressures and loading speeds $[16,17]$ have been investigated in depth in China and abroad, and some great results have been achieved. However, there are few studies regarding the lateral deformation of coal under the same loading rate and different confining pressures. In this study, the TAW-2000 electrohydraulic servo rock mechanics testing machine was employed to examine the deformation characteristics of coal samples under the same loading rate and different confining pressures. Furthermore, the influence of the confining pressure on the lateral deformation characteristics of the coal body was analyzed. The research results combined with the actual measurement results in the underground mine are of great significance to the analysis of the deformation characteristics of the coal body after excavation at a certain buried depth and the selection of reasonable support schemes. At the same time, they can also be utilized as a basis for evaluating the damage of the coal body [18-21].

\section{Sample Preparation and Test Method}

The TAW-2000 electrohydraulic servo rock mechanics testing machine was used in this research. The overall stiffness of the test frame was $10 \mathrm{GN} / \mathrm{m}$, the maximum axial force was $2000 \mathrm{kN}$, and the maximum confining pressure was $100 \mathrm{MPa}$. The dynamic strain monitor and the triaxial test pressure chamber are shown in Figure 1.

The coal samples were selected from the standard specimen made of coal blocks in a coal mine in Shanxi Province of China. The coal blocks obtained from the underground were processed into standard cylindrical coal samples with a diameter of $50 \mathrm{~mm}$ and a height of $100 \mathrm{~mm}$ by using drilling, cutting, and grinding [22-24]. The experimental coal samples are shown in Figure 2. The experimental data were monitored by a high-precision extensometer. Since the extensometer could not resist large deformation, the axial deformation control was adopted in the experiments. The loading speed was set to $0.05 \mathrm{~mm} / \mathrm{min}$, and the test confining pressures were $0 \mathrm{MPa}, 3 \mathrm{MPa}, 5 \mathrm{MPa}$, and $7 \mathrm{MPa}$, respectively. The data of time, load, displacement, stress, axial strain, radial strain, and confining pressure change in the whole process were obtained during the tests [25-27].

To reduce the influence of the heat shrink tube on the experimental results, the same heat shrink tube was employed to package all coal samples in the experiment. The coal samples after the experiment are exhibited in Figure 3.

\section{Analysis of Test Results}

\subsection{Experimental Data Processing.}

(1) Peak strength $\left(\sigma_{c}\right)$ : on the stress-strain curve, the maximum stress (i.e., peak stress) $[28,29]$ is obtained through the following formula:

$$
\delta_{c}=\frac{P_{\max }}{A}
$$

where $P_{\max }$ is the maximum axial load $(\mathrm{N})$ in the test process and $A$ is the compressed area $\left(\mathrm{m}^{2}\right)$ of the sample.

(2) The linear elastic stage: in this stage, the stress and strain on the stress-strain curve have a linear relationship (i.e., their relationship follows Hooke's law).

(3) The nonlinear elastic stage: on the stress-strain curve, it is the section after the linear elastic stage and before the failure of the coal sample.

(4) The plastic deformation stage: in this stage, the weak surface inside the coal body is destroyed, and the stage continues up to the end of the test.

(5) lateral axis ratio: the ratio of the lateral strain to the axial strain of the coal sample during the experiment is called the side axis ratio [30]. 


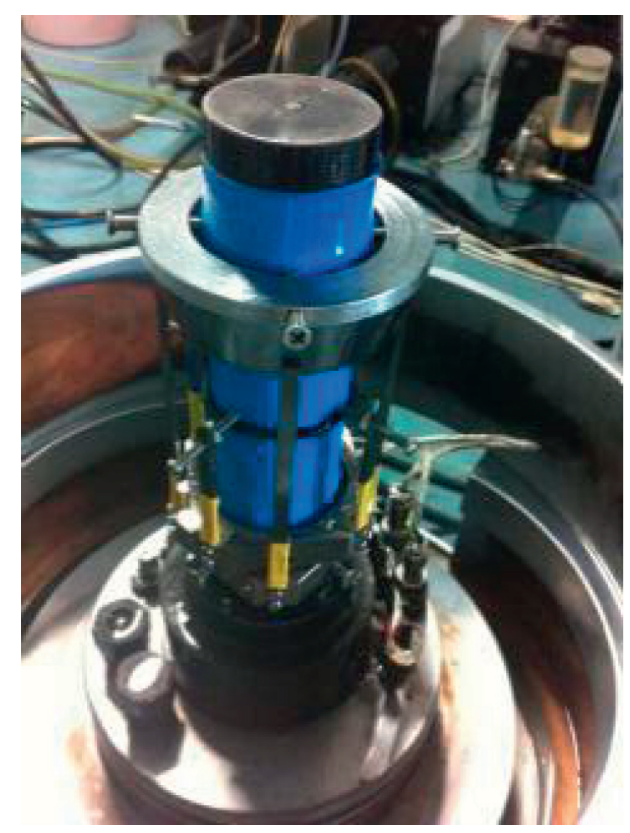

(a)

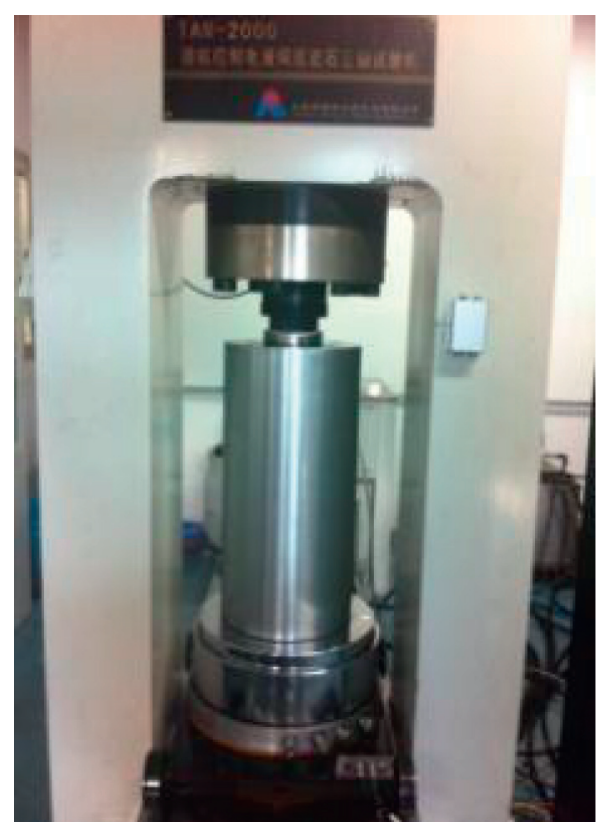

(b)

Figure 1: Test equipment. (a) Dynamic strain monitoring instrument. (b) Pressure chamber of triaxial test.

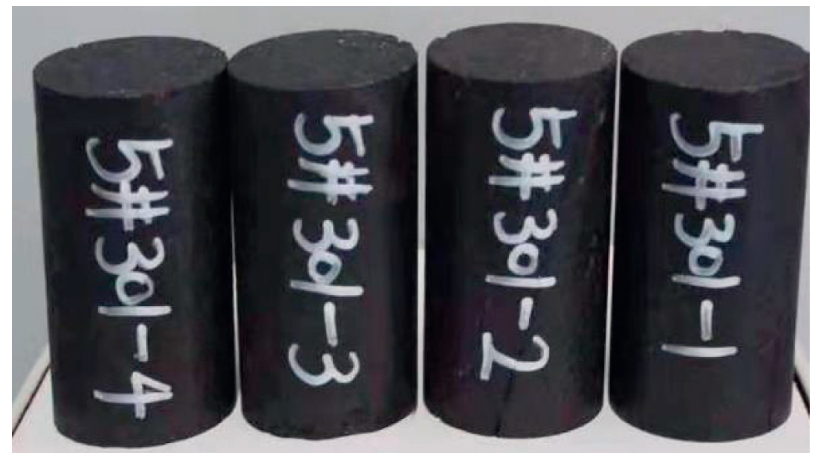

Figure 2: Experimental coal samples.

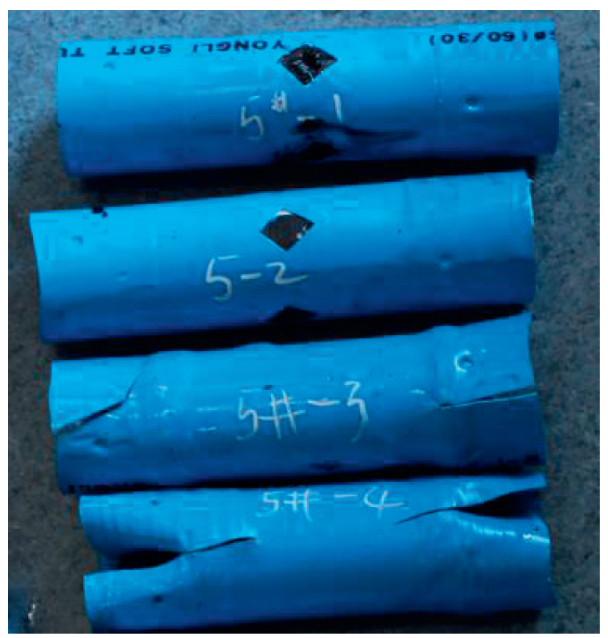

Figure 3: Coal samples after conducting the tests. 
3.2. Analysis of Results. The physical and mechanical parameters of coal samples under different confining pressures are displayed in Table 1. The complete stress-strain curves of coal samples under different confining pressures are shown in Figure 4.

According to the stress-strain curves of coal samples under different confining pressures, coal samples experienced four stages from the beginning of loading to the failure of coal samples (Figure 4): (1) the compaction stage of internal cracks of coal, (2) elastic deformation stage (linear elastic stage and nonlinear elastic stage), (3) plastic deformation stage, and (4) postpeak failure stage.

In the pressure consolidation and compaction stage of cracks, the microcracks inside the coal body were compacted, and the coal had a negative strain in the radial direction, which was characterized as a radial shrinkage. The experimental results indicated that the radial strain developed forward when the stress exceeded $0.83 \mathrm{MPa}$ at $0 \mathrm{MPa}$ confining pressure, $1.36 \mathrm{MPa}$ at $3 \mathrm{MPa}$ confining pressure, $1.78 \mathrm{MPa}$ at $5 \mathrm{MPa}$ confining pressure, and $1.95 \mathrm{MPa}$ at $7 \mathrm{MPa}$ confining pressure.

The coal body entered the linear elastic stage after the pressure consolidation and compaction stage. In this stage, the axial strain and radial strain of the coal body increased according to a certain slope, and the changing trend of the two was consistent. At this stage, the axial and radial stressstrain curves were both straight lines (i.e., the elastic modulus of the coal body was a fixed value). With the increase of stress, the coal entered the nonlinear elastic stage. Compared with the linear elastic stage, the elasticity of coal decreased with the increase of stress, and the strain increased with the increase of stress, which was more obvious with the increase of confining pressure.

With the continuous increase of stress, the weak surface inside the coal body first broke, and the coal body entered the plastic deformation stage. From a large number of experimental test results, we found that there were two types of failure in the loading process of the coal body: (1) The coal body underwent a process of destruction-stabilization-redestruction-restabilizationredestruction caused by the destruction of the weak surface. The stress gradually reached the maximum, and, finally, the main weak surface in the coal body was destroyed, so that the coal body lost its bearing capacity. (2) When the structure of the coal sample was good, there was no stage of restabilization-redestruction, and the failure bearing capacity of the coal from the main weak surface diminished directly. It can be observed from Figure 4 that the first type of failure was more obvious when the confining pressure was $0 \mathrm{MPa}$, and when the confining pressure was nonzero, the coal body mostly showed the second type of failure.

After the peak failure, the coal sample entered the postpeak failure stage, in which both the axial strain and the radial strain increased sharply.

\section{Lateral Deformation Characteristics of Coal under Different Confining Pressures}

4.1. Lateral Deformation Characteristics. To clearly describe the lateral deformation characteristics of the coal under the same loading speed and different confining pressures, the total stress-strain curves of the coal under different confining pressures were plotted. It can be observed from Figure 4 that the axial stress-lateral strain curve and the axial stress-axial strain curve of coal samples under different confining pressures maintained the same changing trend in all four stages. The lateral axis ratio of coal samples under the same loading speed and different confining pressure [31] is shown in Figure 5. The four following stages were observed during the performed tests:

(1) The pressure consolidation and compaction stage of the internal cracks in the coal body: the coal body had radial shrinkage in all four cases. The minimum value of lateral deformation at this stage appeared in the uniaxial compression state and was dominated by radial shrinkage. This showed that, no matter whether or not there was confining pressure, there was a pressure consolidation and compaction process in the radial direction of internal cracks in the coal under axial load. The duration of this stage was short, lasting about three seconds.

(2) Elastic stage: according to Figure 4, the lateral strain range of the coal under $0 \mathrm{MPa}$ confining pressure was $0.091 \times 10^{-3}-3.44 \times 10^{-3}$, and the corresponding axial strain range was $0.377 \times 10^{-3}-4.01 \times 10^{-3}$. Thus, the lateral strain was about $24.1 \%-85.8 \%$ of the axial strain. When the confining pressure was nonzero, the range of the lateral strain and the axial strain of the coal body increased, and the range of the lateral strain of the coal body was the same regardless of the confining pressure, and the lateral strain range was $0.045 \times 10^{-3}-5.06 \times 10^{-3}$. The range of the axial strain under nonzero confining pressure was $0.368 \times$ $10^{-3}-12.44 \times 10^{-3}$. Therefore, the lateral strain range was approximately $12.22 \%-46.9 \%$ of the axial strain range under a nonzero confining pressure. At this stage, the lateral strain was at a low level, and the specimen was mainly subjected to axial compression.

(3) Inelastic stage: in this stage, with the increase of the axial load, the increase rate of the axial strain of the coal sample was greater than that of the lateral strain. The lateral strain of coal under $0 \mathrm{MPa}$ confining pressure was $3.413 \times 10^{-3}-4.33 \times 10^{-3}$, and the corresponding axial strain was $3.991 \times 10^{-3}-4.494 \times 10^{-3}$. Thus, the lateral strain of the specimen was $85.5 \%-96.35 \%$ of the axial strain. Under nonzero confining pressure, the range of lateral strain of coal was $4.107 \times 10^{-3}-10.398 \times 10^{-3}$, and the range of axial strain of coal was 
TABLE 1: Physical and mechanical parameters of coal samples under different confining pressures.

\begin{tabular}{lccccccccc}
\hline Number & $\begin{array}{c}\text { Loading rate } \\
(\mathrm{mm} / \mathrm{min})\end{array}$ & $\begin{array}{c}\text { Diameter } \\
(\mathrm{mm})\end{array}$ & $\begin{array}{c}\text { Height } \\
(\mathrm{mm})\end{array}$ & $\begin{array}{c}\text { Confining } \\
\text { pressure } \\
(\mathrm{MPa})\end{array}$ & $\begin{array}{c}\text { Peak } \\
\text { strength } \\
(\mathrm{MPa})\end{array}$ & $\begin{array}{c}\text { Peak } \\
\text { lateral } \\
\text { strain, } 10^{-2}\end{array}$ & $\begin{array}{c}\text { Peak axial } \\
\text { strain, } \\
10^{-2}\end{array}$ & $\begin{array}{c}\text { Maximum } \\
\text { lateral strain, } \\
10^{-2}\end{array}$ & $\begin{array}{c}\text { Maximum } \\
\text { axial strain, } \\
10^{-2}\end{array}$ \\
\hline M1 & 0.05 & 49.28 & 98.32 & 0 & 12.80 & 0.7667 & 0.5351 & 2.0611 & 0.997 \\
M2 & 0.05 & 49.42 & 98.89 & 3 & 43.95 & 0.6984 & 1.2775 & 1.6062 & 2.0216 \\
M3 & 0.05 & 49.3 & 100.18 & 5 & 53.36 & 0.852 & 1.2412 & 2.6946 & 2.1174 \\
M4 & 0.05 & 49.34 & 100.11 & 7 & 67.43 & 1.0649 & 1.8067 & 2.1468 \\
\hline
\end{tabular}

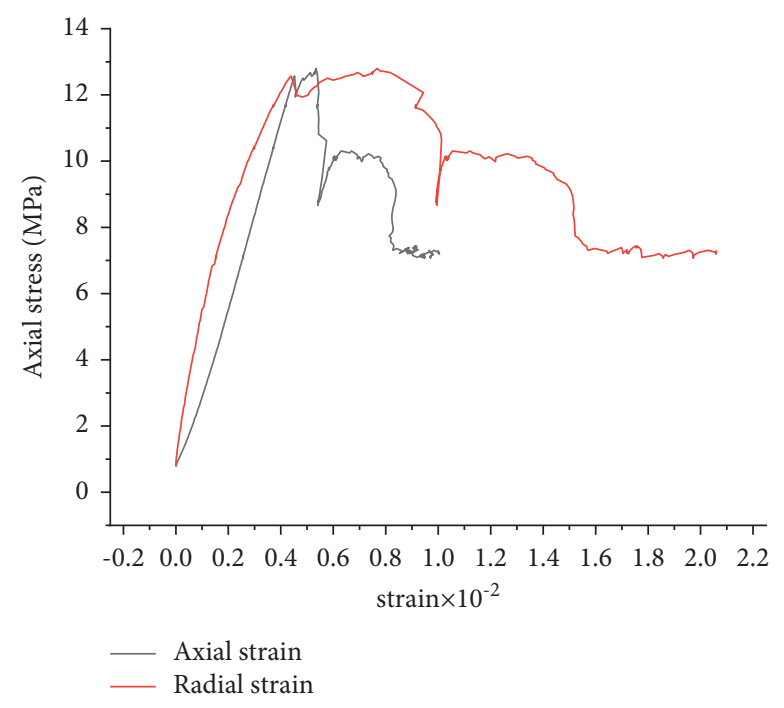

(a)

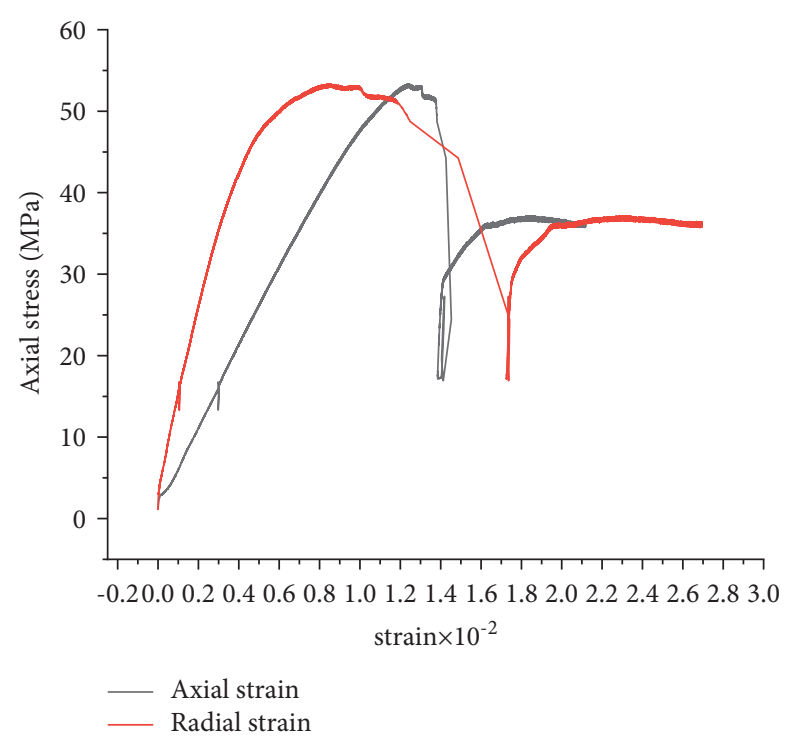

(c)

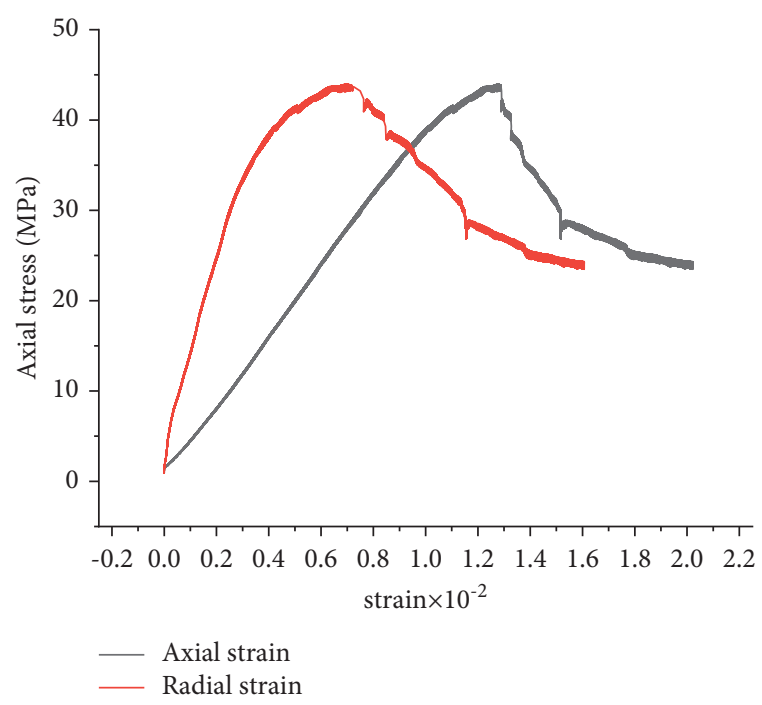

(b)

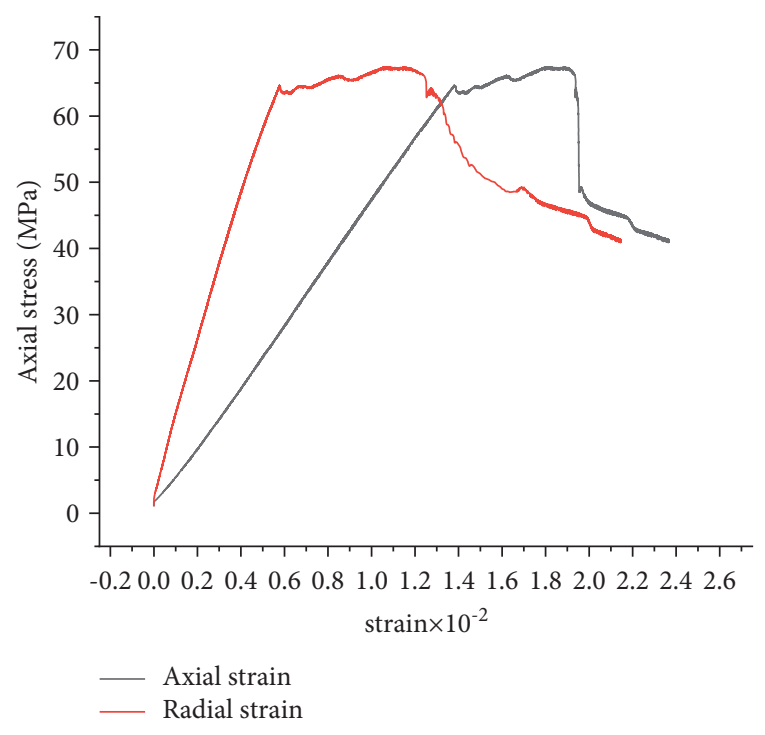

(d)

FIgURE 4: Stress-strain curves under different confining pressures. Stress-strain curve under (a) 0 MPa confining pressure, (b) 3 MPa confining pressure, (c) $5 \mathrm{MPa}$ confining pressure, and (d) $7 \mathrm{MPa}$ confining pressure.

$9.972 \times 10^{-3}-17.811 \times 10^{-3}$. Therefore, the lateral strain of the specimen was $41.18 \%-64.96 \%$ of the axial strain under a nonzero confining pressure. That is, the lateral deformation was slightly smaller than the axial strain at $0 \mathrm{MPa}$; however, it was significantly smaller than the axial deformation when the confining pressure was nonzero.

(4) Postpeak expansion stage: the damage of the coal sample at this stage was chiefly manifested as the damage caused by the development of the weak 


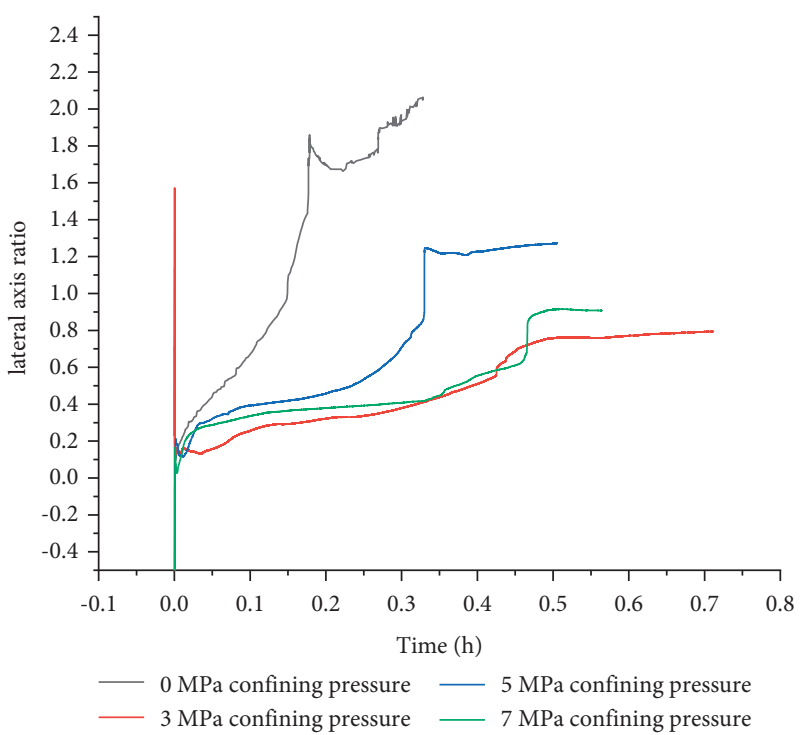

(a)

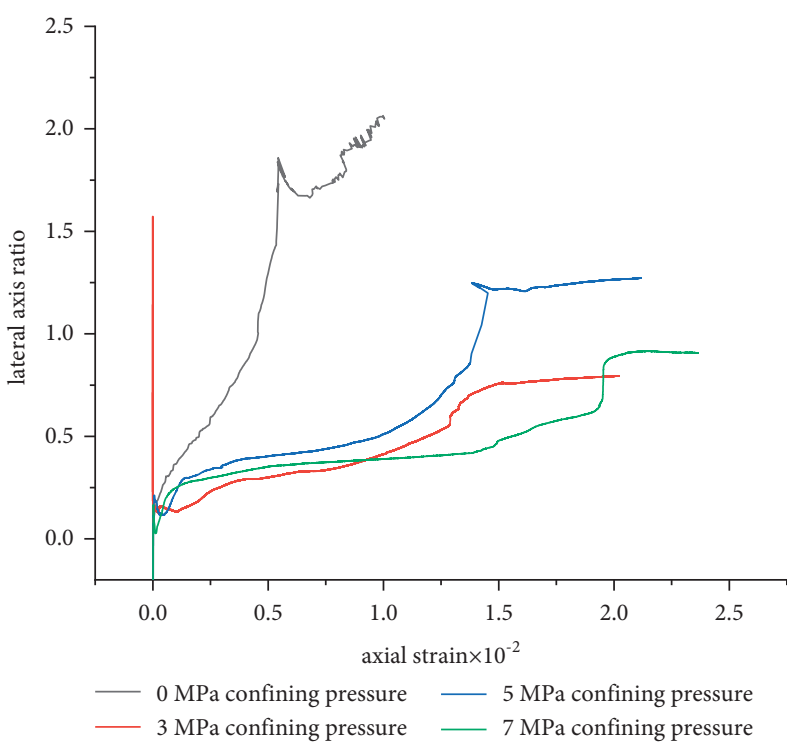

(b)

Figure 5: Characteristic curves of lateral axis ratio of coal sample under different confining pressures. (a) Characteristic curve of lateral axis ratio versus time. (b) Characteristic curve of lateral axis ratio versus axial strain.

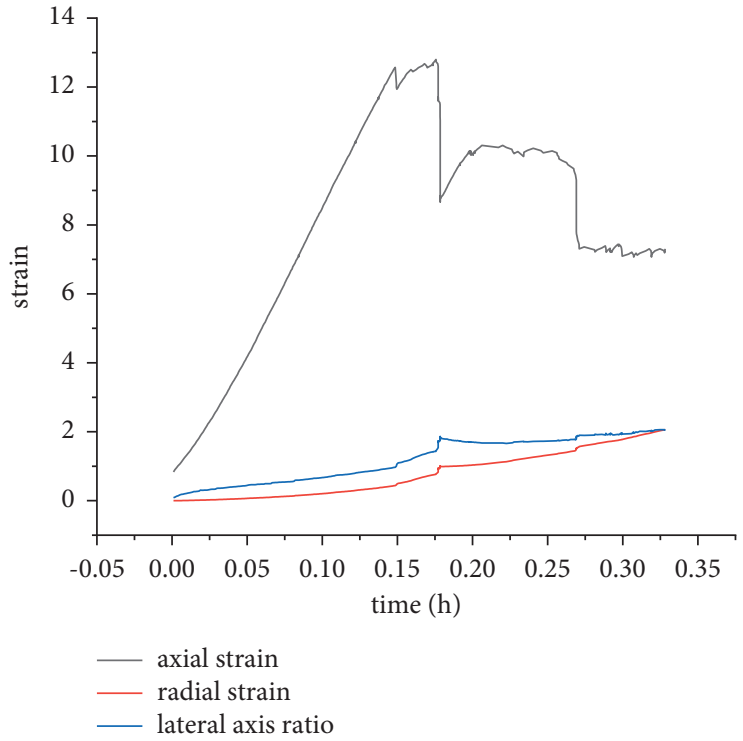

(a)

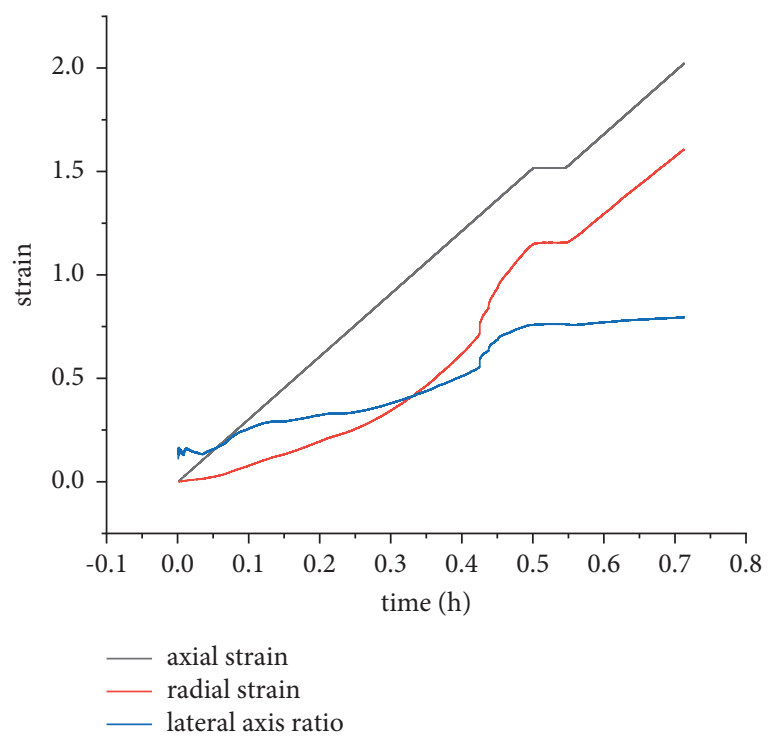

(b)

FIGURE 6: Continued. 


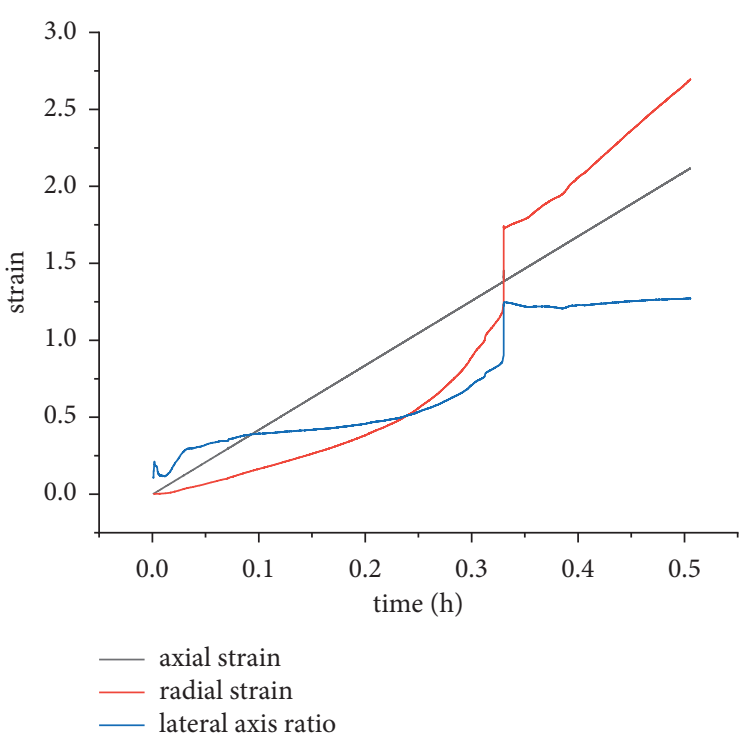

(c)

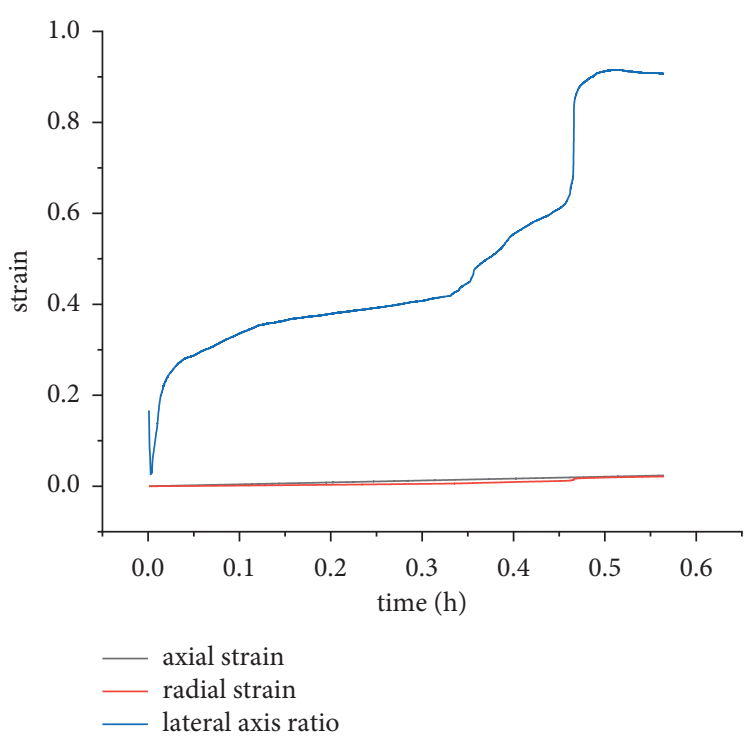

(d)

Figure 6: Time-strain characteristic diagrams of coal sample. Time-strain characteristic diagram under (a) 0 MPa confining pressure, (b) 3 $\mathrm{MPa}$ confining pressure, (c) $5 \mathrm{MPa}$ confining pressure, and (d) $7 \mathrm{MPa}$ confining pressure.

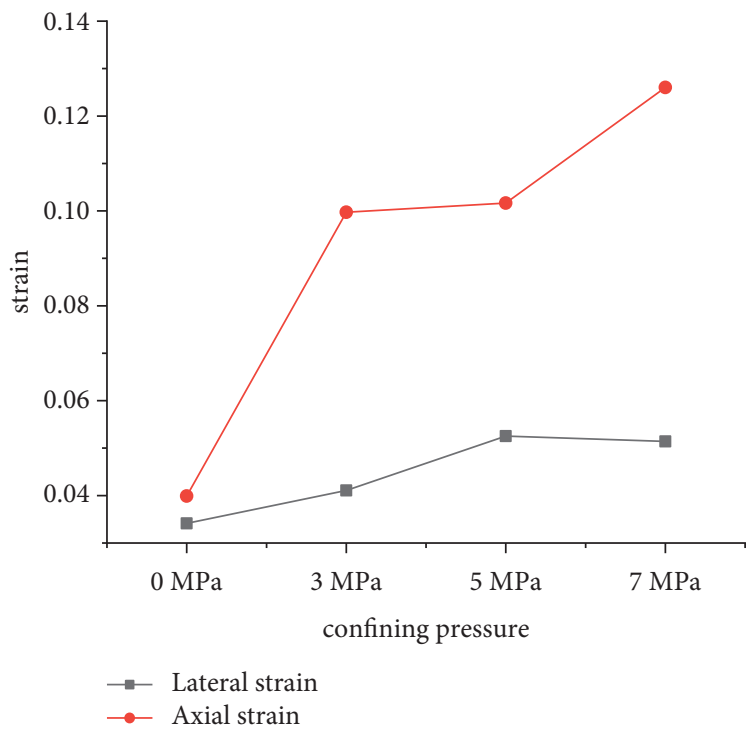

(a)

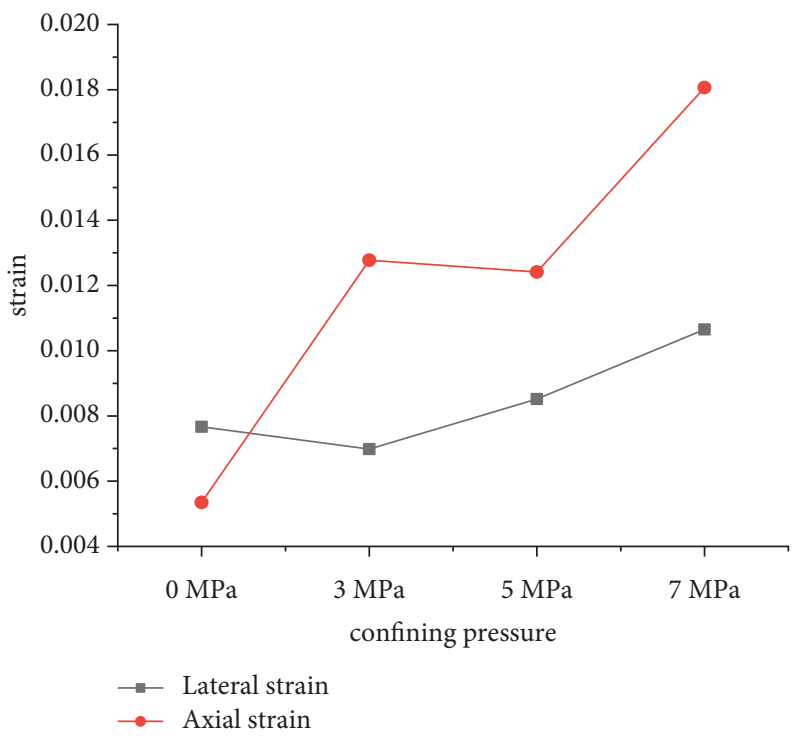

(b)

Figure 7: Peak strain characteristic diagrams. (a) Lateral strain and axial strain at peak stress of elastic deformation. (b) Lateral strain and axial strain at peak stress.

surface inside the coal body towards the failure surface. At this stage, the strength of the coal body decreased rapidly, and the lateral strain increased quickly. The lateral strain at this stage accounted for more than $50 \%$ of the total lateral strain.

4.2. Characteristics of Lateral Axis Ratio. Figures 5(a) and 5(b) show that, before the first stress drop, the lateral axis ratio under $0 \mathrm{MPa}$ confining pressure increased rapidly with time, and the first stress drop occurred in a short time. Furthermore, the lateral axis ratio initially increased slowly with time under the confining pressures of $3 \mathrm{MPa}, 5 \mathrm{MPa}$, and $7 \mathrm{MPa}$, and the lateral axis ratio showed the same change rate. After some time, the lateral axis ratio increased with time up to the point of stress drop. That is, the binding effect of the confining pressure had a great influence on maintaining the stability of the coal body.

4.3. Time-Strain Characteristics. Figure 6 displays the variation trend of axial strain, lateral strain, and lateral axis ratio with time when the coal samples fail under four different confining pressures. It can be observed from the figure that 


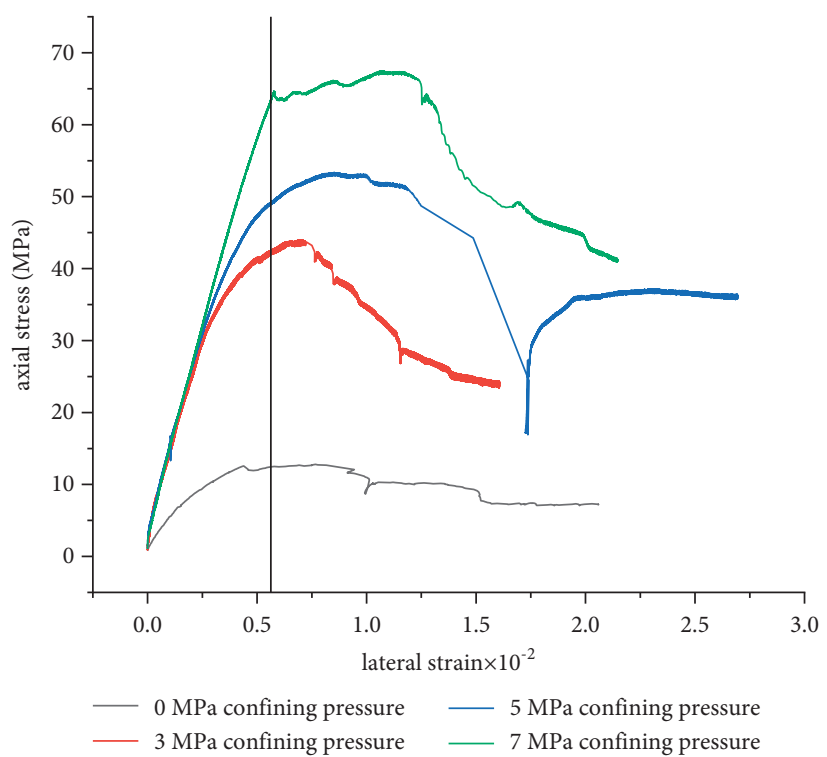

Figure 8: Characteristic curves of axial stress versus lateral strain.

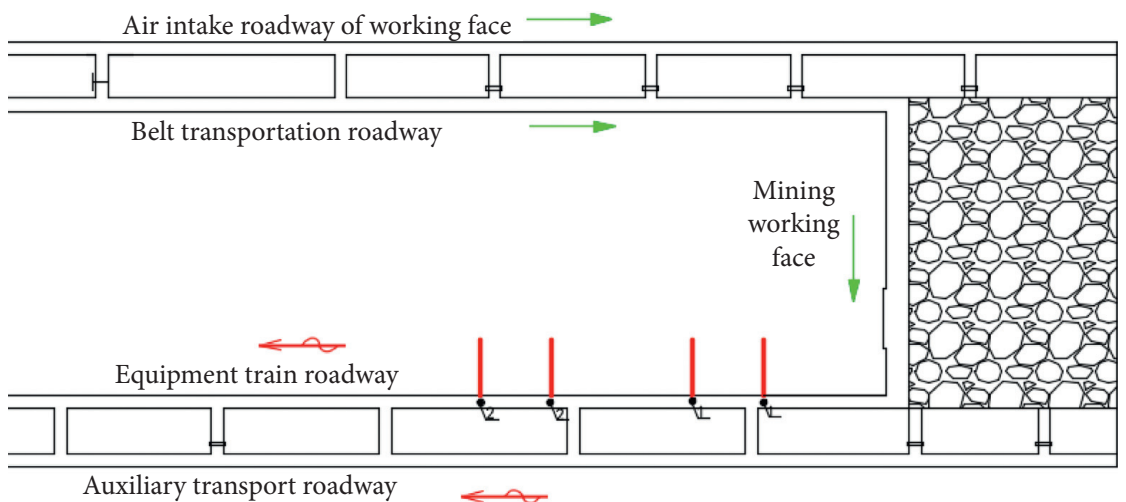

FIgURE 9: Monitoring point layout plan.

the lateral axis ratio curve changed in advance before the lateral failure. At the same time, the linear area where the lateral axis ratio changes with time can be used as a stable area for the deformation of the coal wall of the roadway and the working face, and the area outside the linear area can be utilized as a potential parameter for evaluating the deformation and failure of the coal wall and as a parameter for predicting the failure of the coal body.

4.4. Peak Strain Characteristics. From Figures $7(a)$ and $7(b)$ and Figure 8, it can be observed that when the coal body was destroyed under different confining pressures, the lateral strain was maintained at about $0.6 \times 10^{-2}$.

\section{Engineering Applications}

To verify the reliability of the experimental results, the coal wall of a working face of the No. 5 coal seam of the mine was selected for validation. The deformation of the roadway coal wall in the vertical and horizontal directions was monitored by drilling peep and abscission layer instruments. The experimental location is shown in Figure 9. The test was divided into two groups: In the first group, an anchor net was used with certain confining pressure + steel belt and U-shaped support, respectively, before the lateral strain of the coal wall became equal to $41.18 \%$ of the axial strain. In the second group, after the lateral strain of the coal wall became equal to $64.96 \%$ of the axial strain, the anchor net + steel belt and U-shaped support were used to observe the deformation and failure of the coal wall [32-34]. The destruction of the coal wall is shown in Figure 10 and the monitoring results are displayed in Figure 11.

The field test results showed the following: (1) Supporting before reaching the lateral axis ratio of the failure in the experimental study effectively reduced the deformation and failure of coal wall and increased the stability of coal wall. (2) The existence of confining pressure limited the 


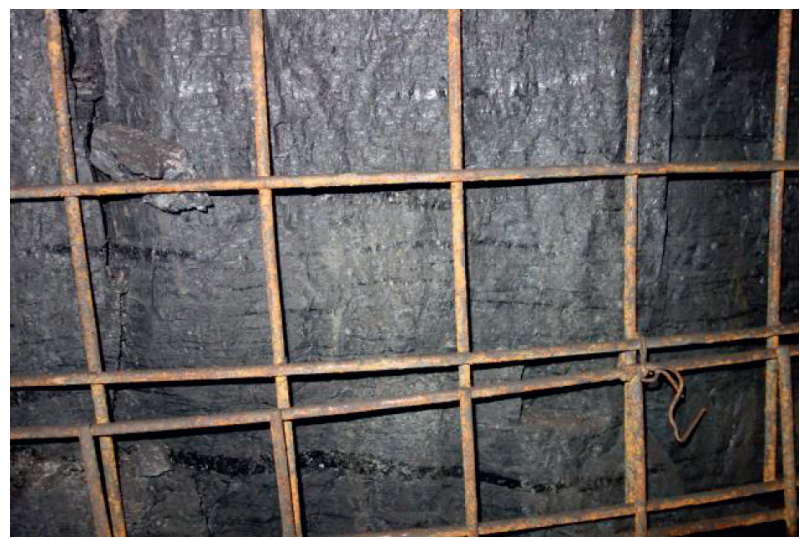

Anchor net + steel belt support

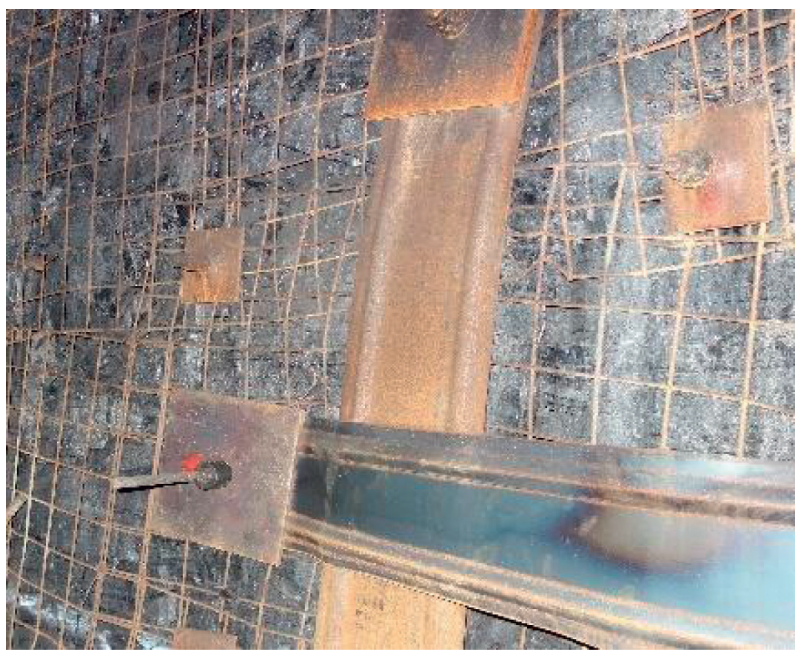

Anchor net + steel belt support

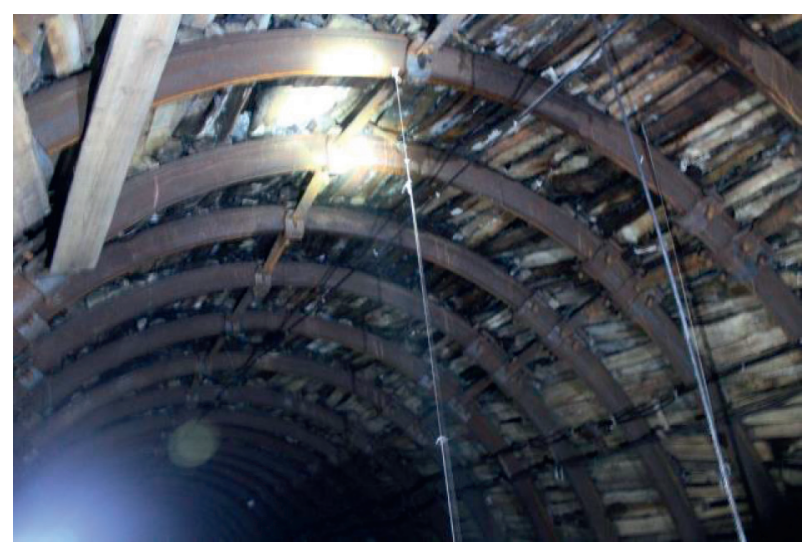

U-shaped support

(a)

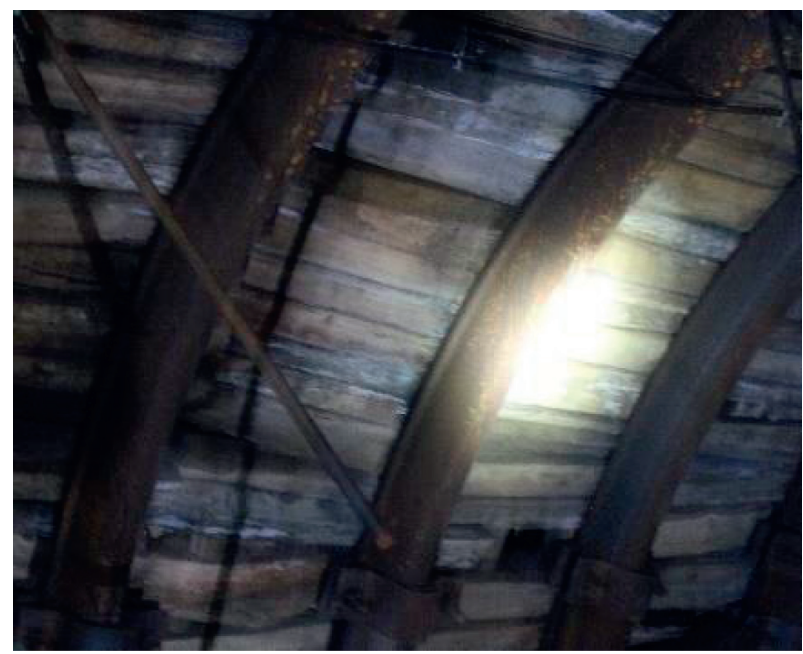

U-shaped support

(b)

Figure 10: Coal wall failure in monitoring points. (a) The first group. (b) The second group.

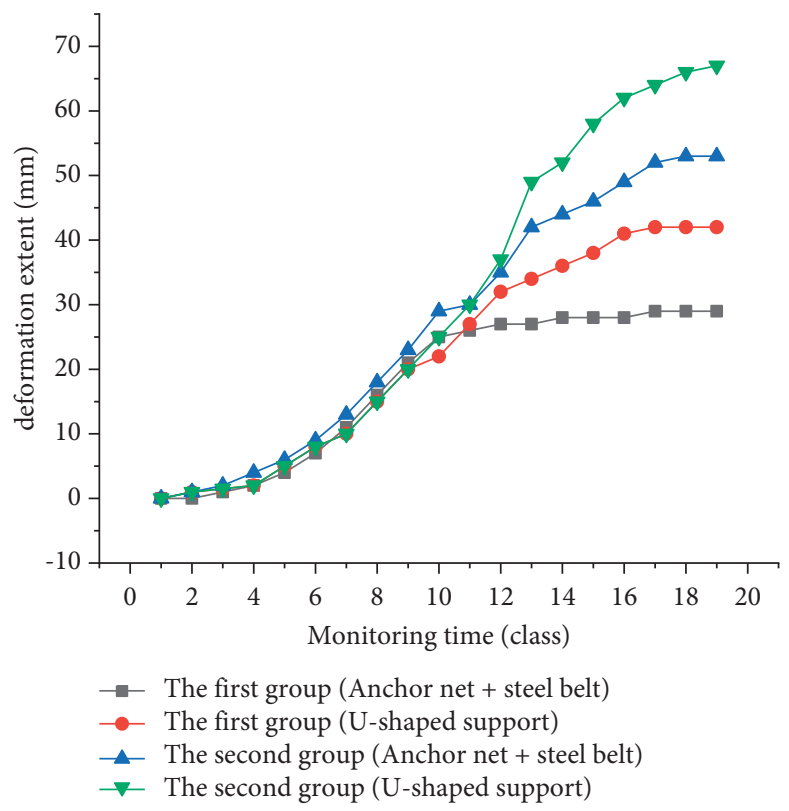

Figure 11: Field curves of deformation versus monitoring time. 
deformation of the coal wall and improved the stability of the coal wall.

\section{Conclusion}

(1) The coal bodies under different confining pressures experienced the whole loading process that ultimately led to the destruction of the coal body. The radial deformation of the coal bodies experienced the internal crack consolidation and compaction stage, the elastic deformation stage, the nonlinear elastic deformation stage, and the postpeak plastic stage. This means that the lateral deformation of the coal body underwent four stages, from shrinkage deformation to linear growth and then to postpeak expansion.

(2) The lateral axis ratios of coal under different confining pressures were different, which could be divided into two categories: under $0 \mathrm{MPa}$ confining pressure, the lateral strain of the coal was about $85.5 \%-96.35 \%$ of the axial strain when it was destroyed. When the confining pressure was nonzero, the lateral strain of the coal mass was about $41.18 \%-64.96 \%$ of the axial strain. When the coal body was destroyed, the lateral strain of the coal was maintained at about $0.6 \times 10^{-2}$.

(3) The field test results indicated that the lateral axis ratio can be used as a potential parameter for evaluating the deformation and failure of coal wall and as a basis for designing the support parameters.

(4) The lateral deformation characteristics of coal under different confining pressures explain why when the same coal seam is mined from shallow to deep, the risk of gas outbursts in coal bodies and the risk of coal wall slicing accidents increase, and the necessity of timely support when excavating underground coal mines becomes more prominent.

\section{Data Availability}

The data used to support the findings of the study are available within the article.

\section{Conflicts of Interest}

The authors declare that they have no conflicts of interest.

\section{Acknowledgments}

This work was financially supported by the Science and Technology Department Joint Fund Project of Guizhou Province, China (Grant no. LH(2017)7036), the first batch of special funds for coal industry transformation and upgrading and gas control of Guizhou Energy Bureau in 2020: Research and application of key technologies of accurate and efficient outburst elimination in high gas and low permeability coal seam area, and the Youth Science and Technology Talent Growth Project of Guizhou Provincial Department of Education (Grant no. ky(2018)414). The authors acknowledge EditSprings (https://www.editsprings. $\mathrm{cn} /$ ) for the expert linguistic services provided.

\section{References}

[1] Y Jingxiang, F. Tao, Z. Yawu, M. Dongyu, and Z. Zeqi, “A new method to evaluate the brittleness of granite based on lateral deformation," Journal of Wuhan University (Engineering Edition), pp. 1-7.

[2] C. Guojun, F. Weiqiang, Z. Daan, Z. Yang, C Shihao, C. Yuhang et al., "Experimental study on the deformation and damage mechanics of sandstone under triaxial cyclic loading," Analysis of Triaxial Cyclic Experimental Results, vol. 45, no. 10, pp. 44-48+747, 2019.

[3] W. Rubin, X. U. Bo, X. U. Weiya et al., "Experimental research on influence of different unloading stress paths on permeability evolution for sandstone," Chinese Journal of Rock Mechanics and Engineering, vol. 38, no. 3, pp. 467-475, 2019.

[4] S. Memetyusup, Z.-d. Zhu, N. I. Xiao-hui, G. Liu, and H. E. Zhi-lei, "Experimental study on deformation failure of sandstone under unloading confining pressure condition," Journal of Hebei University of Engineering (Natural Science Edition), vol. 32, no. 3, pp. 14-30, 2015.

[5] W. Dong, W. Ding, H. Xiaogang et al., "Limestone failure law and post-failure constitutive relation in the control of lateral deformation," Journal of China Coal Society, vol. 35, no. 12, pp. 2022-2027, 2010.

[6] M. Zhenqian, X. Liang, E. Chi, P. Zhang, and X. Xie, "Experimental study on lateral deformation characteristics of coal under different loading rates," Chinese Journal of Applied Mechanics, vol. 37, no. 5, pp. 2007-2012+2320, 2020.

[7] Y. Wu and G. Xicai, "Experimental comparative study on lateral deformation characteristics of coal sample in different loading path," Journal of China Coal Society, vol. 35(S), pp. 44-48, 2010.

[8] Y. Mingqing, Mechanical Properties of rocks, Geological Publishing House, Beijing, China, 2007.

[9] B. Tarasov and Y. Potvin, "Universal criteria for rock brittleness estimation under triaxial compression," International Journal of Rock Mechanics and Mining Sciences, vol. 59, pp. 57-69, 2013.

[10] W. Guo, H. Wang, and S. Chen, "Coal pillar safety and surface deformation characteristics of wide strip pillar mining in deep mine," Arabian Journal of Geosciences, vol. 9, no. 2, pp. 1-9, 2016.

[11] S. Chen, X. Qu, D. Yin et al., "Investigation Lateral Deformation and Failure Characteristics of Strip Coal Pillar in Deep Mining," Geomechanics and engineering, vol. 14, 2018.

[12] S. Chen, H. Wang, Y. Zhu et al., "Monitoring method for coalmass lateral deformation in deep mining and characteristics of step deformation," Chinese Journal of Rock Mechanics and Engineering, vol. 35, no. S2, pp. 4121-4128, 2016.

[13] Z. Zhang and F. Gao, "Confining pressure effect on rock energy," Chinese Journal of Rock Mechanics and Engineering, vol. 34, no. 1, pp. 1-11, 2015.

[14] L. I. Xi-bing, C Zheng-hong, C. A. O. Wen-zhuo, and M. Tao, "ZHOU Jian Time-effect properties and mechanisms of marble failure under different unloading rates," Chinese Journal of Geotechnical Engineering, vol. 39, no. 9, pp. 1565-1574, 2017.

[15] Yu Wang, L. I. Xiao, Y. Wu et al., "Research on relationship between crack initiation stress level and brittleness indices for brittle rocks," Chinese Journal of Rock Mechanics and Engineering, vol. 33, no. 2, pp. 264-275, 2014. 
[16] M. A. Zhen-qian, Y.-d. Jiang, L. I. Yan-wei, Y.-m. Yang, and L. I. Hai-tao, "Experimental research on influence of loading rate and confining pressure on energy evolution of coal," Chinese Journal of Geotechnical Engineering, vol. 38, no. 11, pp. 2114-2121, 2016.

[17] Y. Wang, X. Liu, D. Chen, D. Wang, Y. Yang, and D. Chen, "Damage characteristics of outburst coal sample containing gas under different loading rates," Safety In Coal Mines, vol. 51, no. 6, pp. 25-30, 2020.

[18] X. Yingjie, L. Lianchong, T. Chun'an et al., "Rock brittleness evaluation based on stress dropping rate after peak stress and energy ratio," Chinese Journal of Rock Mechanics and Engineering, vol. 35, no. 6, pp. 1141-1154, 2016.

[19] C. Guo-qing, C. Zhao, W. Tao et al., "Evaluation method of rock brittlecharacteristics based on full stress-strain curve and crack initiation stress," Chinese Journal of Rock Mechanics and Engineering, vol. 37, no. 1, pp. 51-59, 2018.

[20] Q. Wang, M. C. He, S. C Li et al., "Comparative study of model tests on automatically formed roadway and gob-side entry driving in deep coal mines," International Journal of Mining Science and Technology, vol. 31, no. 4, pp. 591-601, 2021.

[21] Q. Wang, Y. Wang, M. He et al., "Experimental research and application of automatically formed roadway without advance tunneling," Tunnelling and Underground Space Technology, vol. 114, Article ID 103999, 2021.

[22] T. Wang, Z. Ma, P. Gong, N. Li, and S. Cheng, "Analysis of failure characteristics and strength criterion of coal-rock combined body with different height ratios," Advances in Civil Engineering, vol. 2020, Article ID 8842206, 14 pages, 2020.

[23] Q. Yin, J. Wu, C. Zhu, M. He, Q. Meng, and H. Jing, "Shear mechanical responses of sandstone exposed to high temperature under constant normal stiffness boundary conditions," Geomechanics and Geophysics for Geo-Energy and GeoResources, vol. 7, no. 2, p. 35, 2021.

[24] F. Gan, Y. Kang, X.-c. Wang et al., "Investigation on the failure characteristics and fracture classification of shale under Brazilian test conditions," Rock Mechanics and Rock Engineering, vol. 53, no. 7, pp. 3325-3340, 2020.

[25] C. X. Zhang, B. Dai, and W. U. Qiu-Hong, "Analysis on deformation properties and energy dissipation of rock unloading failure process under different stress path," Journal of Safety Science and Technology, vol. 10, no. 10, pp. 35-40, 2014.

[26] F. Wu, H. Zhang, Q. Zou, C. Li, J. Chen, and R. Gao, "Viscoelastic-plastic damage creep model for salt rock based on fractional derivative theory," Mechanics of Materials, vol. 150, Article ID 103600, 2020.

[27] F. Gan, X. Wang, M. Wang et al., "Experimental investigation of thermal cycling on fracture characteristics of granite in a geothermal-energy reservoir," Engineering Fracture Mechanics, vol. 235, Article ID 107180, 2020.

[28] X. Hao, L. Yuan, Y. Li et al., "Lateral deformation characteristics of coal with bump tendency based on uniaxial compression experiment," Zhongguo Kuangye Daxue Xuebao/ Journal of China University of Mining and Technology, vol. 47, no. 1, pp. 129-136, 2018.

[29] H. . Wagner, "Determination of the Complete Load-Deformation Characteristics of Coal Pillars," Congress of the International Society for Rock Mechanics 3, Lisboa: Laboratório nacional de engenharia civil, Lisbon, Portugal, 1974.

[30] Xianjie, L. Yuan, Y. Li et al., "Lateral deformation characteristics of coal with bump tendency based on uniaxial compressions experiment," Journal of China university of mining \& technology, vol. 47, no. 1, pp. 129-136, 2018.
[31] pengbo Lv, Study on Mechanical Characteristics and Damage Laws of Coal Samples under Different loading, Henan Polytechnic University, Jiaozuo, China, 2018.

[32] L. I. Bin-Yu, M. Bai, and Y. C. Bian, "Analysis on Support Reinforcement for Lateral Deformation of Coal Transporting Trestle," Coal Engineering, vol. 47, no. 7, pp. 33-35, 2015.

[33] C. Zhu, M. C. He, X. H. Zhang, Z. G. Tao, Q. Yin, and L. F. Li, "Nonlinear mechanical model of constant resistance and large deformation bolt and influence parameters analysis of constant resistance behavior," Rock and Soil Mechanics, vol. 42, no. 7, pp. 1911-1924.

[34] F. Wang, S. Yin, A. Guo et al., "Frame structure and engineering applications of the multisource system cloud service platform of monitoring of the soft rock tunnel," Geofluids, vol. 2021, no. 3, 15 pages, Article ID 6672732, 2021. 